\title{
CARACTERIZACCÃO DE ATRIBUTOS DE SOLOS AO LONGO DE UMA TOPOSSEQUENCIA EM AMBIENTE DE CAMPINARANA NA AMAZÔNIA SUL OCIDENTAL, BRASIL
}

\author{
Sebastião dos Santos Pereira \\ Administrador Florestal da Vert Shoes, Campo Bom, Rio Grande do Sul \\ sebastiao.mapia@gmail.com \\ Edson Alves de Araújo \\ Universidade Federal do Acre, Campus Floresta, Cruzeiro do Sul, Acre \\ earaujo.ac@gmail.com \\ Willian Carlos de Lima Moreira \\ Universidade Federal do Acre, Campus Sede, Mestrando em Produção Vegetal, Rio Branco, Acre \\ willian.carloss@hotmail.com \\ Nilson Gomes Bardales \\ Universidade Federal do Acre, Campus Sede, Rio Branco, Acre \\ nilsonbardales@gmail.com \\ Eliane de Oliveira \\ Universidade Federal do Acre, Campus Floresta, Cruzeiro do Sul, Acre \\ elicanga@gmail.com
}

\section{RESUMO}

As Campinaranas são fitofisionomias que ocorrem na Amazônia e na região do Vale do Juruá, em domínio de solos arenosos e utilizados frequentemente para exploração mineral e agrícola. Objetivou-se caracterizar atributos de solo em uma topossequencia de ambiente de Campinarana Florestada de modo a subsidiar sua utilização de forma racional. Este trabalho foi realizado no município de Cruzeiro do Sul, Acre, em área de solos originados de arenitos da Formação Cruzeiro do Sul. $\mathrm{Na}$ área de estudo foram abertos três perfis de solo: topo, meia encosta e baixada. Os solos foram descritos e coletados para análises físicas e químicas de rotina. A classificação taxonômica foi realizada conforme o Sistema Brasileiro de Classificação de Solos. No topo constatou-se Neossolo Quartzarênico, um intergrade na meia encosta e Espodossolo Humilúvico na baixada. As análises físicas evidenciaram maiores proporções de areia nos perfis estudados, com predomínio da fração areia grossa, que favorecem a lixiviação, baixa capacidade de armazenamento de água e suscetibilidade à erosão. Os solos são pobres em nutrientes, com alta saturação de alumínio, e maior proporção de matéria orgânica no horizonte Espódico. Os solos e o ambiente estudados são altamente sucetíveis a degradação, se mal utilizados, sendo recomendados como áreas de conservação.

Palavras-chave: Vale do Juruá. Formação Cruzeiro do Sul. Espodossolos. Neossolos Quartzarênicos.

\section{CHARACTERIZATION OF SOIL ATTRIBUTES ALONG A TOPOSSEQUENCE IN A CAMPINARANA ENVIRONMENT IN SOUTH WESTERN AMAZON, BRAZIL}

\begin{abstract}
Campinaranas are natural ecosystems which have sandy material as substrate, mainly Spodosols. In the Jurua Valley these environments are used for mineral exploitation and agricultural activities. The objective was to characterize soil attributes in a Campinarana geoenvironment in order to aid its rational use. This study was conducted in the municipality of Cruzeiro do Sul, state of Acre, in a patch derived from sandstones of the Cruzeiro do Sul geological formation. For this study, we used the toposequence procedure, i.e., we studied the soil taking into account the pedologic forms of the environment. From the area study, we opened three soil profiles: in the top, medium slope and lower region. The soils were described and the samples were collected for physical and chemical analyses. The taxonomic classification was conducted according to the Brazilian Soil Classification System. At the top was found the Quartzipsamment, at the lower region a Spodosol and at the medium slope a mix of both soils. The soil physical analyses revealed higher sand proportions in the profiles studied, with predominance of coarse sand, which favours the nutrients leaching, low water holding capacity and increase the susceptibility to soil erosion. The soils are poor in nutrients, with high aluminium concentration and higher organic matter proportion in the spodic horizon. The studied soils and environment are highly susceptible to degradation, if misused, being recommended as conservation areas.
\end{abstract}

Keywords: Juruá Valley. Cruzeiro do Sul geological Formation. Spodosols. Quartzipsamments. 


\section{INTRODUÇÃO}

Campinas e Campinaranas são encontradas ocupando cerca de $180.000 \mathrm{~km}^{2}$ no território brasileiro (IBGE, 2000) e 7\% da Amazônia Legal (DALY e PRANCE, 1989). Apresentam vegetação típica, endêmica com grande heterogeneidade estrutural e florística entre as diferentes regiões de ocorrência (VICENTINI, 2004). As campinaranas são consideradas vegetação clímax (SCHAEFER et al., 2009), apresentando diferentes densidades vegetacional, variando de Campinarana Florestada a Campinarana Arborizada e Campinarana Gramíneo-Lenhosa (VELOSO et al., 1991). O Manual Técnico da Vegetação Brasileira (IBGE, 1992), considerando o porte dos dosséis e exuberância das formações vegetais, classifica as fitofisionomias associadas às Campinaranas, em Campinaranas Florestadas, Campinaranas Arborizadas, Campinaranas Gramíneo-lenhosas e Campinas.

As campinaranas são ecossistemas Amazônicos cuja fitofisionomia está intimamente relacionada com a sazonalidade e com a variação do lençol freático (MENDONÇA et al., 2015). O termo campinarana refere-se a um complexo de vegetação com formação não florestal com sub-bosque de porte baixo e irregular (ACRE, 2010). Na região Amazônica esses ecossistemas ocorrem principalmente associados à bacia do Rio Negro (GUIMARÃES e BUENO, 2016). No Vale do Juruá, Acre, verifica-se a ocorrência em algumas regiões dos municípios de Mâncio Lima e Cruzeiro do Sul, que se estende ao município de Guajará (AM), além de algumas manchas menores próximo aos municípios de Porto Walter e Marechal Thaumaturgo (BRITO et al., 2017). A localização geográfica da região possibilita a existência de uma flora específica e endêmica, com influência das terras baixas, dos solos arenosos e também dos Andes (DALY e SILVEIRA, 2002; DALY et AL., 2008). Comparação da flora das áreas de Campinaranas do Acre com levantamentos realizados na Amazônia peruana e nas regiões central e oriental da Amazônia brasileira, desconsiderando ervas, epífitas e palmeiras, apresentaram diferenças na composição e dominância taxonômica com mais de 90\% de dissimilaridade (DALY et al., 2016). Comparando esses três conjuntos de dados florísticos, 184 espécies e 45 gêneros foram únicos na amostragem da Amazônia Central e Oriental, 138 espécies e 43 gêneros foram únicos no conjunto restrito ao Acre, e 160 espécies e 56 gêneros foram únicos no conjunto de Amazônia peruana.

Esse tipo de vegetação se desenvolve sobre solos oligotróficos, ou seja, que apresentam elevados teores de areia e baixa fertilidade natural, além de serem solos hidromórficos e ricos em ácido húmico (ACRE, 2010). Normalmente as Campinaranas ocorrem predominantemente associadas a ambientes de Espodossolos e Neossolos Quartzarênicos (MENDONÇA et al., 2015).

Os Neossolos Quartzarênicos apresentam a sequência de horizontes A-C com textura areia ou areia franca em todos os horizontes a no mínimo $150 \mathrm{~cm}$ da superfície, com a fração areia tendo mais que $95 \%$ de Quartzo. Os Espodossolos são solos que apresentam a sequência de horizontes A, E, B espódico e C, com textura predominantemente arenosa, baixa fertilidade, moderado a fortemente ácidos, com elevados teores de alumínio trocável e baixa saturação por bases (SANTOS et al., 2018).

Esses ambientes apresentam fragilidade em razão da ocorrência de menor diversidade de espécies florestais quando comparados com outros ambientes amazônicos, entretanto as quais se configuram como áreas com espécies endêmicas e suscetíveis à ação antrópica (BRITO et al., 2017). Conforme aumenta o grau de hidromorfismo, as campinaras com vegetação florestada vão sendo substituídas por campinaranas arborizada, campinaranas gramíneo-lenhosas até essencialmente herbáceas com característica de brejos (MENDONÇA et al., 2015). Daly et al. (2016) propõem a existência de nove formações vegetacionais diferenciadas as quais são encontradas no complexo vegetacional sobre areia branca do estado do Acre. Os autores sugerem que atributos edáficos atuam como principais fatores seletivos da estrutura vegetal das distintas fitofisionomias. Geralmente nas campinas há maior diversidade de espécies vegetais em relação a campinaranas, devido ao fato de nas áreas de campinas haver uma maior penetração de luz, o que é impedido nas campinaranas arbóreas (FERREIRA et al., 2013). A heterogeneidade e complexidade estrutural do ambiente de areias brancas pode ser responsável pelas variações na cobertura vegetal (DIAS et al., 2017).

Apesar de ser considerado um ambiente ácido e de baixa fertilidade, a absorção e ciclagem de nutrientes pelas plantas ocorre de forma eficiente, permitindo a manutenção das espécies vegetais (OLIVEIRA et al., 2001).

As diferentes fitofisionomias sobre as areias branca do Acre contemplam significativa proporção das espécies vegetais acreanas (7,3\% das distribuições não generalizadas) restritas às campinaranas (DALY et al., 2008), entretanto apesar de ser um ambiente único diferenciado em termos florísticos, ecológicos e pedológicos, e que ocorrem em diversas regiões da Amazônia, em especial na região do alto Rio Negro, são ainda pouco estudados (MENDES et al., 2017). 
São essencialmente ecossistemas arenícolas que funcionam como um grande reservatório de carbono na camada superficial do solo (MENDONÇA et al., 2015). No entanto, em algumas regiões Amazônicas as áreas com predomínio de campinaranas estão sendo impactadas devido a algumas ações antrópicas, principalmente pela extração de areia utilizada na construção civil, que geralmente resultam em crateras profundas (FERREIRA et al., 2013)

Na região do Vale do Juruá, as áreas de campinaranas são utilizadas para a extração de areia para a construção civil, causando danos ao ecossistema, pois uma vez removida a vegetação original e a camada superficial, a capacidade de restauração do sistema pode ficar comprometida (SILVA e ARAÚJO, 2020; FILGUEIRA et al., 2020). A agricultura familiar é praticada em algumas áreas sob campinaranas, com o cultivo de espécies menos exigentes em fertilidade do solo, como a mandioca e abacaxizeiro.

Nesse contexto o presente trabalho teve por objetivo realizar o estudo de atributos morfológicos, físicos e químicos de solos de uma topossequencia como subsídios a classificação taxonômica e ao uso racional dos solos de ambiente de Campinarana Florestada do município de Cruzeiro do Sul, Acre.

\section{METODOLOGIA}

\section{ÁREA DE ESTUDO}

O estudo foi realizado no município de Cruzeiro do Sul, Acre, pertencente à regional de desenvolvimento do Juruá. O clima da região é do tipo Af (quente e úmido), segundo a classificação de Köppen, com temperatura média anual de $24^{\circ} \mathrm{C}$ e chuvas bem distribuídas ao longo do ano, com ausência da estação seca definida, com precipitação média anual de 2.109 mm (ACRE, 2010).

O relevo da região varia de plano a suave ondulado, com ocorrência da formação de Campinaranas do tipo Florestada, que caracteriza-se por apresentar vegetação com porte mais elevado e maior cobertura do dossel em relação às campinaras arbustivas (ACRE, 2010; GUIMARÃES e BUENO, 2016).

A área está sob o domínio geológico da Formação Cruzeiro do Sul, cujos sedimentos foram depositados no período do Quaternário $(1,75 \mathrm{Ma})$, a partir de correntes fluviais, fluviolacustres e leques aluviais (CAVALCANTE, 2005). Estes sedimentos estão distribuídos em áreas de terraços e são constituídos por arenitos finos e médios, friáveis, maciços e argilosos, com intercalações de argilitos (Figura 1). A geomorfologia é constituída pela Superfície Tabular de Cruzeiro do Sul (altitude média de $150 \mathrm{~m}$ à $270 \mathrm{~m}$ ) e a Planície Amazônica altitude entre $110 \mathrm{~m}$ e $270 \mathrm{~m}$, situada ao longo dos principais rios (ACRE, 2010).

Figura 1 - Estratos sedimentares da Formação Cruzeiro do Sul, Cruzeiro do Sul, Acre.

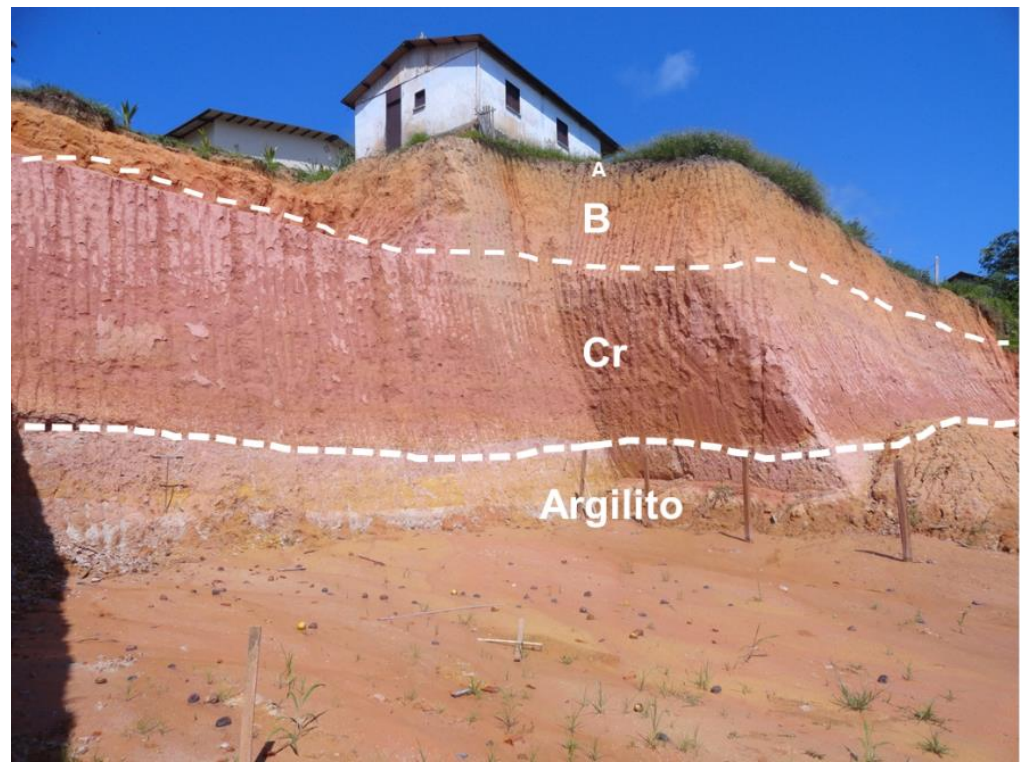

Fonte: Os autores 


\section{TRABALHO DE CAMPO}

A metodologia utilizada para prospecção, descrição morfológica e coleta de solo a campo foi realizada conforme preconiza o Manual de Descrição e Coleta de Solo no Campo (SANTOS et al., 2013). Na prospecção à campo foram realizadas 10 tradagens até $1 \mathrm{~m}$ de profundidade para coleta de amostras de solo a fim de verificar alguns atributos morfológicos como a cor (MUNSELL, 1994), textura, drenagem e presença de concreções. A etapa de prospecção serviu de base seleção dos locais representativos para a abertura de três trincheiras em topossequência (Figura 2), nas dimensões de $1,5 \mathrm{~m} \times 1,5 \mathrm{~m} \times 1,5 \mathrm{~m}$. A classificação dos solos foi realizada até o quarto nível categórico de acordo com o atual Sistema Brasileiro de Classificação de Solos - SiBCS (SANTOS et al., 2018).

Figura 2 - A) Localização da área de estudo e dos perfis de solo. B) Esquema de distribuição das trincheiras em topossequência.
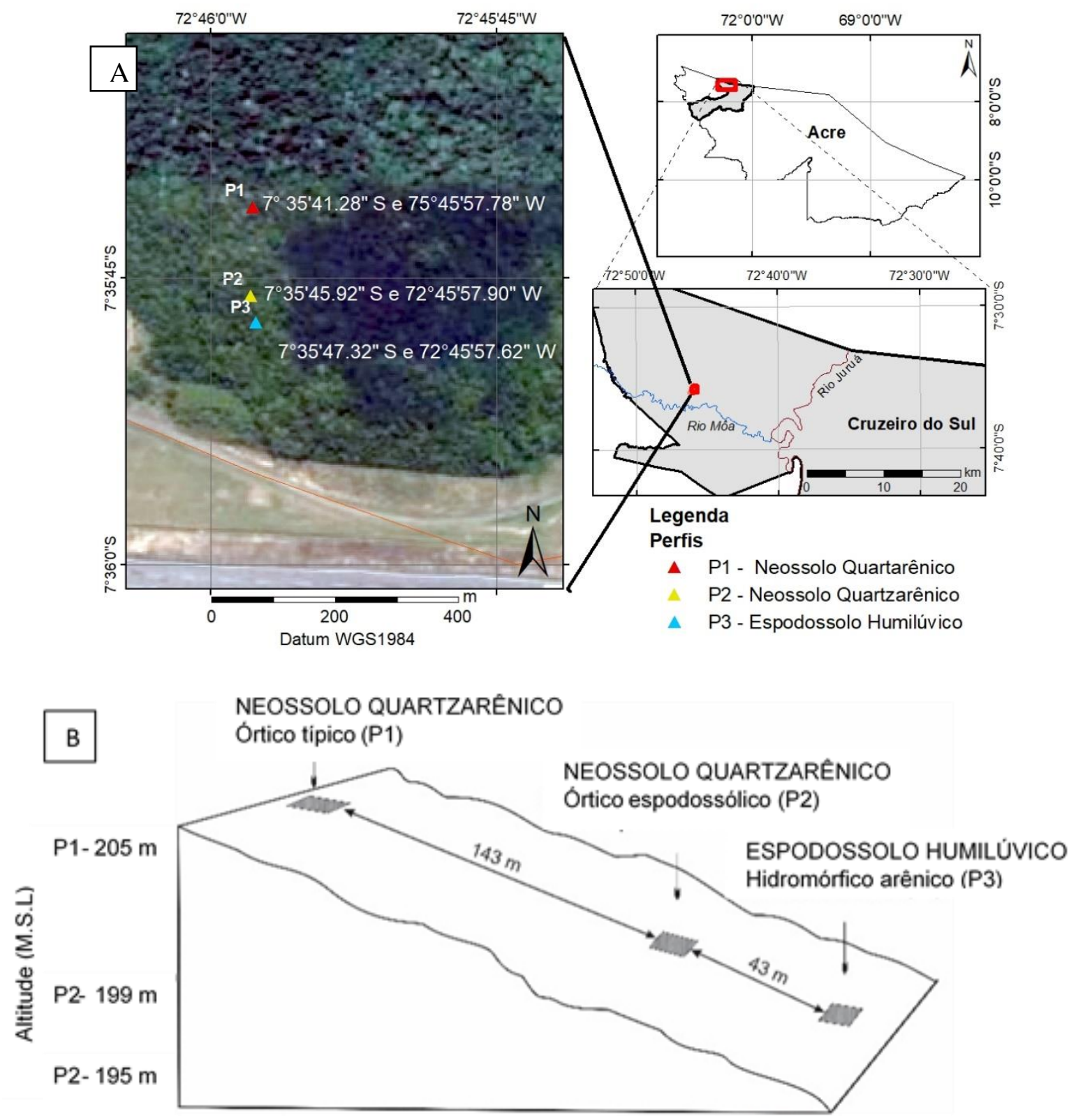

Fonte: Os autores. 


\section{ANÁLISES LABORATORIAIS}

Em cada horizonte pedogenético foram coletadas amostras de solo para fins de análises físicas e químicas, sendo uma amostra para cada respectivo horizonte dos três perfis descritos totalizando 18 amostras, que foram realizadas de acordo com a metodologia proposta no Manual de Métodos de Análise de Solo (TEIXEIRA et al., 2017). As análises físicas consistiram em: textura (proporções relativas de areia, silte e argila) (método da pipeta), argila dispersa em água (argila natural) (método da pipeta) e densidade do solo (método do anel volumétrico) e de partículas (método do balão volumétrico). O grau de floculação (GF) foi determinado através da expressão: GF = [(argila totalargila dispersa em água) / argila total)] x 100. As análises químicas consistiram em $\mathrm{pH}$ em $\mathrm{H}_{2} \mathrm{O}$ e $\mathrm{KCl}$ (proporção solo solução: 1:2,5), cálcio, magnésio, e alumínio trocável (método do $\mathrm{KCl} 1 \mathrm{~mol} \mathrm{~L}^{-1}$ ), potássio (extração com solução Mehlich-1 e determinação por espectrofotometria de chama), $\mathrm{H}+\mathrm{Al}$ (extração com acetato de cálcio tamponado a pH 7,0 e determinação volumétrica com solução de $\mathrm{NaOH}$ ), fósforo (mehlich-1), carbono orgânico (método do dicromato de potássio), e fósforo remanescente (método do cloreto de cálcio). A partir dos dados foram obtidas as demais relações: delta $\mathrm{pH}\left(\mathrm{pH} \mathrm{KCl}-\mathrm{pH} \mathrm{H}{ }_{2} \mathrm{O}\right)$; soma de bases $(\mathrm{Ca}+\mathrm{Mg}+\mathrm{K})$; CTC efetiva (t) $(\mathrm{SB}+\mathrm{Al})$; CTC potencial (T) $(\mathrm{SB}+\mathrm{H}+\mathrm{Al})$; saturação por bases: $\mathrm{V} \%=(\mathrm{SB} / \mathrm{CTC})$; saturação por alumínio $\mathrm{m} \%=(\mathrm{Al} / \mathrm{t})$ e matéria orgânica (Carbono orgânico x 1,72).

Os resultados das análises químicas foram comparados e interpretados de acordo com os valores propostos por Wadt e Cravo (2005) e Amaral e Souza (1998), sendo divididos em parâmetros de disponibilidade, levando em consideração as condições de solos do estado do Acre.

\section{RESULTADOS E DISCUSSÃO}

\section{ATRIBUTOS MORFOLÓGICOS}

Os perfis descritos na topossequência apresentam cores predominantemente brunadas e acinzentadas em todos os horizontes. O P1 (Neossolo Quartzarênico Órtico típico) se diferencia em profundidade com cores amareladas a partir de $81 \mathrm{~cm}$ da superfície (Figura 3). As cores amareladas presentes são atribuídas a presença do óxido de ferro Goethita, que assim como a Hematita (avermelhada), são minerais de grande ocorrência nos solos tropicais (DALMOLIN et al,. 2005).

Figura 3 - Mosaico dos perfis de solo descritos na topossequência. P1 - NEOSSOLO QUARTZARÊNICO Órtico típico; P2 - NEOSSOLO QUARTZARÊNICO Órtico espodossólico; P3 - ESPODOSSOLO HUMILÚVICO Hidromórfico arênico.
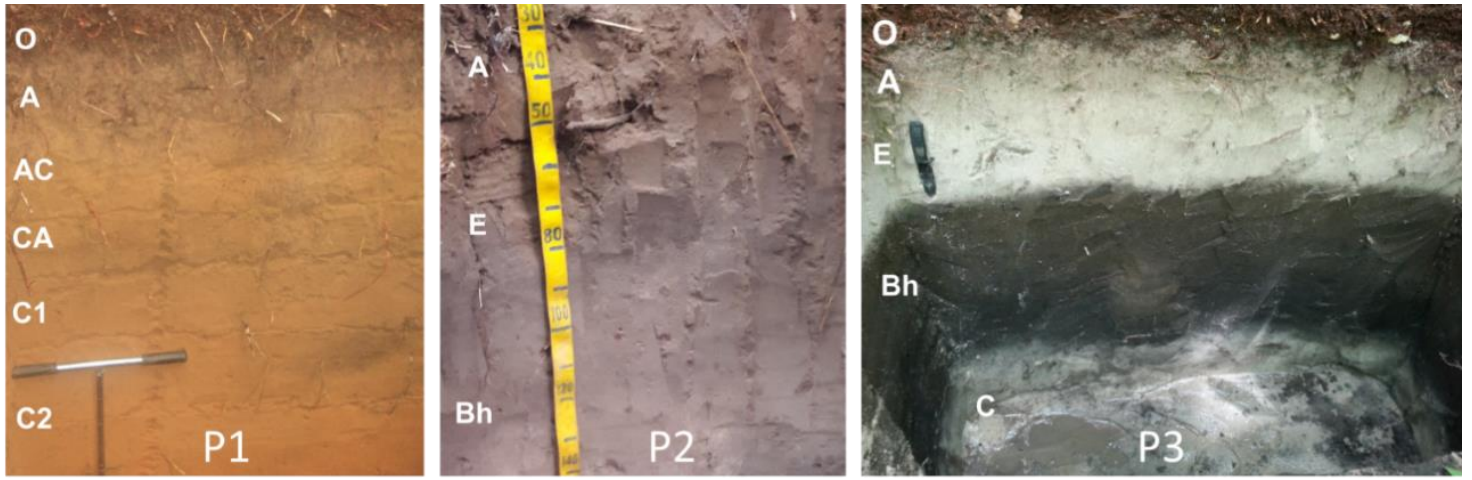

Fonte: Os autores.

A intensa lixiviação de minerais de argila e matéria orgânica contribuem para coloração escura e o caráter predominantemente arenoso em toda extensão dos perfis (Quadro 1). Nota-se que a coloração escura no P1 (Neossolo Quartzarênico Órtico típico) nos horizontes A, AC e CA são oriundas da combinação da fração mineral com a matéria orgânica. Nos horizontes Bh dos perfis 2 e 3 as cores escuras são resultantes da acumulação iluvial de matéria orgânica e alumínio. O alumínio está presente nos horizontes B espódicos, sendo essencial pra que ocorra sua formação, podendo haver presença de ferro, que da mesma forma que os outros materiais foram translocados dos 
Caracterização de atributos de solos ao longo de uma topossequencia em ambiente de Campinarana na Amazônia Sul Ocidental, Brasil
Sebastião dos Santos Pereira

Edson Alves de Araújo

Willian Carlos de Lima Moreira

Nilson Gomes Bardales Eliane de Oliveira

horizontes superiores (SANTOS et al., 2018). A condição de elevação e rebaixamento do lençol freático atua de forma direta no processo de redução e lixiviação desses elementos (GUIMARÃES e BUENO, 2016).

Quadro 1 - Atributos morfológicos de uma topossequência em área de Campinarana Florestada.

\begin{tabular}{|c|c|c|c|c|c|c|c|}
\hline \multicolumn{8}{|c|}{ P1- NEOSSOLO QUARTZARÊNICO Órtico típico } \\
\hline \multirow{2}{*}{ Horizonte } & \multirow{2}{*}{ Prof. (cm) } & \multirow{2}{*}{\multicolumn{2}{|c|}{ Cor $\underline{(1)}$}} & \multirow{2}{*}{$\begin{array}{c}\text { Classe } \\
\text { textural }(2)\end{array}$} & \multicolumn{2}{|c|}{ Estrutura } & \multirow{2}{*}{ Drenagem } \\
\hline & & & & & Tipo & Grau & \\
\hline $\mathrm{O}$ & $-20-0$ & & - & - & - & - & \multirow{6}{*}{ Bem drenado } \\
\hline A & $0-18$ & $\begin{array}{c}7,5 \mathrm{YR} \\
3 / 2\end{array}$ & bruno escuro & areia & - & gs & \\
\hline$A C$ & $18-42$ & $\begin{array}{c}7,5 \mathrm{YR} \\
5 / 3\end{array}$ & bruno escuro & areia & - & gs & \\
\hline $\mathrm{CA}$ & $42-81$ & $\begin{array}{c}7,5 \text { YR } \\
4 / 4\end{array}$ & bruno & areia & - & ma & \\
\hline $\mathrm{C} 1$ & $81-112$ & $\begin{array}{c}7,5 \text { YR } \\
5 / 6 \\
\end{array}$ & bruno forte & areia & - & ma & \\
\hline $\mathrm{C} 2$ & $112-180+$ & $\begin{array}{c}7,5 \mathrm{YR} \\
5 / 8\end{array}$ & bruno forte & areia franca & - & ma & \\
\hline \multicolumn{8}{|c|}{ P2 - NEOSSOLO QUARTZARÊNICO Órtico espodossólico } \\
\hline 0 & $-6-0$ & & - & - & - & - & \multirow{8}{*}{$\begin{array}{c}\text { Moderadamente } \\
\text { drenado }\end{array}$} \\
\hline$A$ & $0-14$ & 10 YR $5 / 3$ & bruno & areia & - & gs & \\
\hline$A C$ & 14-33 & $10 R 5 / 3$ & bruno & areia & - & gs & \\
\hline $\mathrm{C} 1$ & $33-57$ & 10 YR 4/4 & $\begin{array}{c}\text { bruno } \\
\text { amarelado } \\
\text { escuro }\end{array}$ & areia & - & gs & \\
\hline Bh1 & $57-70$ & 10 YR $4 / 4$ & $\begin{array}{c}\text { bruno } \\
\text { amarelado } \\
\text { escuro }\end{array}$ & areia & - & gs & \\
\hline $\mathrm{Bh} 2$ & $70-111$ & $10 \mathrm{YR} 3 / 2$ & $\begin{array}{c}\text { bruno } \\
\text { acinzentado } \\
\text { muito escuro }\end{array}$ & areia & - & gs & \\
\hline $\mathrm{BhC}$ & $111-140$ & 10 YR 4/3 & bruno & areia & - & gs & \\
\hline $\mathrm{C}$ & $140-193+$ & $5 Y 7 / 1$ & cinzento claro & areia & - & gs & \\
\hline \multicolumn{8}{|c|}{ P3 - ESPODOSSOLO HUMILÚVICO Hidromórfico arênico } \\
\hline $\mathrm{O}$ & $-20-0$ & & - & - & - & - & \multirow{7}{*}{$\begin{array}{l}\text { Imperfeitamente } \\
\text { drenado }\end{array}$} \\
\hline A & $0-10$ & 10 YR 5/3 & bruno & areia & - & gs & \\
\hline$E$ & $10-33$ & 10YR $7 / 2$ & cinzento claro & areia & - & gs & \\
\hline Bh1 & $33-61$ & 10YR 2/2 & $\begin{array}{l}\text { bruno muito } \\
\text { escuro }\end{array}$ & areia & sub & mo & \\
\hline Bh2 & $61-77$ & 10YR 3/2 & $\begin{array}{c}\text { bruno } \\
\text { acinzentado } \\
\text { muito escuro }\end{array}$ & areia franca & - & gs & \\
\hline Bh3 & $77-94$ & 10YR 2/1 & preto & areia & sub & mo & \\
\hline $\mathrm{C}$ & $94-125+$ & 10YR $4 / 1$ & $\begin{array}{l}\text { cinzento } \\
\text { escuro }\end{array}$ & areia franca & - & gs & \\
\hline
\end{tabular}

Notação: ma: maciço; gs: grãos simples; sub: blocos subangulares; mo: moderada.

Fonte: Dados da pesquisa adaptados conforme 1: Munsell (1994); 2: Santos et al. (2013). 
A drenagem torna se deficiente à medida que se desloca para regiões mais baixas ( $P$ 1 para o $P 3$ ), se aproximando da rede de drenagem e sofrendo influência da flutuação lençol freático. A profundidade do horizonte $\mathrm{Bh}$ pode atuar como barreira impedindo a drenagem do perfil em situações onde se apresenta endurecido, denominado de Ortstein.

\section{ATRIBUTOS FísICOS}

As proporções de areia total são superiores a $800 \mathrm{~g} / \mathrm{kg}$ em todos os perfis, caracterizando estes como solos predominantemente de textura arenosa. Os valores da fração argila estão abaixo de $91 \mathrm{~g} / \mathrm{kg} \mathrm{em}$ toda as seções dos perfis, com tendência a um leve aumento em profundidade. Verifica-se que há aumento no teor de areia grossa e redução no teor de areia fina, conforme se direciona do P1 para o P3, tanto em superfície como em subsuperfície (Tabela 1).

Tabela 1 - Atributos físicos de solos de uma topossequência em ambiente de Campinarana Florestada.

\begin{tabular}{|c|c|c|c|c|c|c|c|c|c|c|}
\hline \multirow{2}{*}{ Horiz. } & $\begin{array}{l}\text { Prof. } \\
\text { (cm) }\end{array}$ & $\begin{array}{c}\text { Areia } \\
\text { grossa }\end{array}$ & $\begin{array}{c}\text { Areia } \\
\text { fina }\end{array}$ & Silte & $\begin{array}{c}\text { Argila } \\
\text { total }\end{array}$ & $\begin{array}{c}\text { Argila } \\
\text { dispersa }\end{array}$ & GF(\%) & Dp & Ds & $\begin{array}{c}\text { Porosidade } \\
\text { total }\end{array}$ \\
\hline & \multicolumn{6}{|c|}{$\mathbf{g} / \mathbf{k g}$} & $\%$ & \multicolumn{2}{|c|}{$\mathrm{g} / \mathrm{cm}^{3}$} & $\mathrm{~cm}^{3} / 100 \mathrm{~cm}^{3}$ \\
\hline \multicolumn{11}{|c|}{ P1- NEOSSOLO QUARTZARÊNICO Órtico típico } \\
\hline$A$ & $0-18$ & 680 & 210 & 46 & 65 & 7 & 89 & 2,64 & 1,45 & 45 \\
\hline$A C$ & $18-42$ & 607 & 271 & 40 & 82 & 6 & 93 & 2,67 & 1,34 & 50 \\
\hline CA & $42-81$ & 585 & 279 & 49 & 87 & 13 & 85 & 2,70 & 1,44 & 48 \\
\hline $\mathrm{C} 1$ & $81-112$ & 620 & 248 & 51 & 80 & 1 & 99 & 2,71 & 1,45 & 46 \\
\hline $\mathrm{C} 2$ & $112-180$ & 628 & 229 & 71 & 72 & 27 & 63 & 2,66 & 1,45 & 45 \\
\hline \multicolumn{11}{|c|}{ P2 - NEOSSOLO QUARTZARÊNICO Ortico espodossólico } \\
\hline A & $0-14$ & 730 & 195 & 39 & 37 & 1 & 97 & 2,70 & 1,41 & 48 \\
\hline$A C$ & 14-33 & 669 & 224 & 45 & 62 & 4 & 94 & 2,70 & 1,55 & 43 \\
\hline $\mathrm{C} 1$ & $33-57$ & 665 & 239 & 15 & 80 & 8 & 90 & 2,80 & 1,59 & 43 \\
\hline Bh1 & $57-70$ & 584 & 250 & 86 & 80 & 6 & 93 & 2,63 & 1,45 & 45 \\
\hline Bh2 & $70-111$ & 591 & 276 & 56 & 77 & 4 & 95 & 2,61 & 1,49 & 43 \\
\hline $\mathrm{BhC}$ & 111-140 & 689 & 231 & 53 & 40 & 5 & 88 & 2,73 & 1,60 & 41 \\
\hline $\mathrm{C}$ & 140-193 & 636 & 248 & 53 & 62 & 18 & 71 & 2,70 & 1,55 & 43 \\
\hline \multicolumn{11}{|c|}{ P3 - ESPODOSSOLO HUMILÚVICO Hidromórfico arênico } \\
\hline $\bar{A}$ & $0-10$ & 762 & 159 & 64 & 15 & 2 & 85 & 2,71 & $1,1,55$ & 43 \\
\hline $\mathrm{E}$ & 10_33 & 749 & 166 & 62 & 24 & 2 & 92 & 2,80 & 1,66 & 41 \\
\hline B1h & $33-61$ & 684 & 171 & 66 & 78 & 2 & 98 & 2,64 & 1,38 & 47 \\
\hline B2h & $61-77$ & 680 & 165 & 66 & 90 & 0 & 100 & 2,64 & 1,34 & 49 \\
\hline B3h & $77-94$ & 709 & 162 & 59 & 71 & 2 & 97 & 2,67 & 1,32 & 51 \\
\hline $\mathrm{C}$ & $94-125$ & 544 & 293 & 76 & 87 & 2 & 98 & 2,67 & 1,45 & 46 \\
\hline
\end{tabular}

GF: grau de floculação; Dp: densidade de partículas; Ds: densidade do solo.

Fonte: Dados da pesquisa.

A textura arenosa dos perfis da topossequência pode ser oriunda do intemperismo dos arenitos da Formação Cruzeiro do Sul (CAVALCANTE, 2005), bem como pela presença de areias Quartzosas inconsolidadas que se encontram sobrepostas a Formação Cruzeiro do Sul e que estão próximas da área de estudo. Estes materiais são comumente encontrados na região noroeste do município de Cruzeiro do Sul (ACRE, 2010). A textura mais grosseira torna essas áreas de relevante interesse mineral na extração de areia para a construção civil na região do Vale do Juruá (DALL'IGNA e SILVA, 2015). A fração areia grossa encontra-se em maiores proporções em relação a areia fina. Isso denota que durante o processo de deposição dos sedimentos devem ter predominado águas mais turbulentas. Como a área deste trabalho encontra-se próximo ao rio Moa, não se deve descartar que os materiais 
depositados possam ter sido originados a partir de materiais quartzosos depositados em interflúvios tabulares em época pretérita.

Os teores de argila variam entre $15 \mathrm{~g} / \mathrm{kg}$ e $65 \mathrm{~g} / \mathrm{kg}$ em superfície. Verifica-se que ocorre uma diminuição dos teores de argila do perfil 1 para o 3 em superfície e nos três primeiros horizontes (correspondendo a cerca de 0,6 $\mathrm{m}$ da superfície). Ou seja, na sequência Neossolo - Espodossolo, ocorre redução gradual no conteúdo de argila nos primeiros horizontes do solo, entretanto abaixo de 0,6 $\mathrm{m}$ o conteúdo de argila apresenta distribuição desuniforme na topossequência.

Com exceção dos horizontes $\mathrm{C}$ e $\mathrm{C} 1$ dos perfis 1 e 2, respectivamente, o grau de floculação é superior a $85 \%$, indicando que mesmo com baixo conteúdo, a argila se encontra pouco dispersa. Entretanto, o alto conteúdo de areia, que é uma fração que não forma agregados, torna o solo suscetível a erosão. Os elevados valores de grau de floculação indicam que há baixo conteúdo de argila dispersa em água (TEIXEIRA et al., 2017) e normalmente utiliza-se para inferir o grau de estabilidade de agregados do solo.

\section{ATRIBUTOS QUÍMICOS}

Os valores de $\mathrm{pH}$ em $\mathrm{H}_{2} \mathrm{O}$ são considerados baixos, caracterizando-se como acidez elevada $(\mathrm{pH}<5)$ em todos os horizontes dos perfis 1 e 3 , e nos dois primeiros horizontes do perfil 2 (Tabela 2). No perfil 1, com exceção do horizonte $A$, os valores de delta pH são positivos. Já no perfil 2 e 3 , os valores de delta $\mathrm{pH}$ são negativos. $\mathrm{O}$ delta $\mathrm{pH}$ é um indicador da condição de cargas elétricas no solo, ao passo que se têm valores positivos $\left(\mathrm{pH} \mathrm{KCl}>\mathrm{pH} \mathrm{H} \mathrm{H}_{2} \mathrm{O}\right)$, indica maior predomínio de cargas positivas, e do contrário $\left(\mathrm{pH} \mathrm{H} \mathrm{H}_{2} \mathrm{O}>\mathrm{pH} \mathrm{KCl}\right)$ as cargas negativas predominam nos colóides (LIMA et al., 2016). Dessa forma solos com valores negativos tendem a reter com maior facilidade os íons de carga positiva, a exemplo das bases trocáveis cálcio, magnésio e potássio, que são assimiladas pelas plantas.

Tabela 2 - Atributos químicos de uma topossequência em área de campinarana.

\begin{tabular}{|c|c|c|c|c|c|c|c|c|c|}
\hline \multirow{2}{*}{ Hor. } & \multirow{2}{*}{$\begin{array}{l}\text { Prof. } \\
\text { (cm) }\end{array}$} & \multicolumn{2}{|c|}{$\mathrm{pH}$} & \multirow{2}{*}{$\begin{array}{c}\mathrm{P} \\
\mathrm{mg} / \mathrm{kg}\end{array}$} & \multirow[t]{2}{*}{$\mathbf{K}$} & \multirow[t]{2}{*}{$\mathrm{Ca}$} & \multirow{2}{*}{\multicolumn{2}{|c|}{$\begin{array}{c}\mathrm{Mg} \\
\mathrm{cmol}_{\mathrm{c}} / \mathrm{kg}\end{array}$}} & \multirow[t]{2}{*}{$\mathbf{H}+\mathbf{A}$} \\
\hline & & $\mathrm{H}_{2} \mathrm{O}$ & $\mathrm{KCl}$ & & & & & & \\
\hline \multicolumn{10}{|c|}{ P1 - NEOSSOLO QUARTZARÊNICO Órtico típico } \\
\hline A A & $0-18$ & 3,4 & 3,4 & 1 & 0,03 & 0,05 & 0,1 & 2,1 & 111,3 \\
\hline$A C$ & $18-42$ & 4,3 & 4,5 & 1 & 0,02 & 0,04 & 0,1 & 0,4 & 4,3 \\
\hline $\mathrm{CA}$ & $42-81$ & 4,8 & 5,9 & 1 & 0,01 & 0,06 & 0,1 & 0,3 & 3,5 \\
\hline $\mathrm{C} 1$ & $81-112$ & 4,5 & 4,9 & 1 & 0,02 & 0,03 & 0,1 & 0,2 & 2,3 \\
\hline $\mathrm{C} 2$ & $112-180$ & 4,6 & 4,7 & 0 & 0,01 & 0,07 & 0,1 & 0,1 & 1,6 \\
\hline \multicolumn{10}{|c|}{ P2 - NEOSSOLO QUARTZARÊNICO Órtico espodossólico } \\
\hline$A$ & $0-14$ & 4,5 & 3,4 & 5 & 0,16 & 0,05 & 0,1 & 0,7 & 2,6 \\
\hline$A C$ & $14-33$ & 4,5 & 4,8 & 4 & 0,16 & 0,05 & 0,1 & 0,9 & 4,3 \\
\hline C1 & $33-57$ & 5,7 & 4,8 & 3 & 0,22 & 0,1 & 0,1 & 0,0 & 1,1 \\
\hline Bh1 & $57-70$ & 5,2 & 4,8 & 2 & 0,23 & 0,12 & 0,1 & 0,4 & 3,5 \\
\hline $\mathrm{Bh} 2$ & $70-111$ & 5,5 & 4,7 & 3 & 0,23 & 0,12 & 0,1 & 0,3 & 2,3 \\
\hline $\mathrm{BhC}$ & $111-140$ & 5,4 & 4,8 & 3 & 0,12 & 0,03 & 0,1 & 0,3 & 1,6 \\
\hline $\mathrm{C}$ & $140-193$ & 5,4 & 4,5 & 1 & 0,19 & 0,09 & 0,1 & 0,4 & 1,3 \\
\hline \multicolumn{10}{|c|}{ P3 - ESPODOSSOLO HUMILÚVICO Hidromórfico arênico } \\
\hline $\bar{A}$ & $0-10$ & 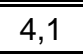 & 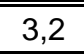 & 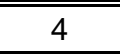 & 0,02 & 0,11 & 0,1 & 0,4 & 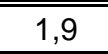 \\
\hline $\mathrm{E}$ & 10_33 & 4,8 & 4,2 & 1 & 0,02 & 0,08 & 0,1 & 0,1 & 1,1 \\
\hline B1h & $33-61$ & 4,8 & 4,5 & 1 & 0,01 & 0,07 & 0,1 & 0,4 & 8,0 \\
\hline $\mathrm{B} 2 \mathrm{~h}$ & $61-77$ & 5,0 & 4,1 & 2 & 0,02 & 0,11 & 0,1 & 1,4 & 10,5 \\
\hline B3h & $77-94$ & 4,9 & 4,5 & 1 & 0,01 & 0,09 & 0,1 & 0,7 & 6,4 \\
\hline $\mathrm{C}$ & $94-125$ & 4,6 & 4,5 & 1 & 0,01 & 0,07 & 0,1 & 0,6 & 5,3 \\
\hline
\end{tabular}


Os teores de $\mathrm{Ca}^{+2}$ e $\mathrm{Mg}^{+2}$ são considerados baixos em todos os horizontes. Os valores de CTC potencial em superfície reduzem do P1 para o P3, podendo estar relacionado com a redução do teor de argila e matéria orgânica (M.O.) (Tabela 3). A saturação de bases aumenta do perfil 1 para o perfil 3 por consequência da redução da CTC, em todos os casos se caracterizando como solos distróficos. A matéria orgânica é um componente que exerce papel fundamental na manutenção da CTC do solo (CUNHA et al., 2015). Entretanto, como observado por Guimarães et al. (2018) os horizontes com maior conteúdo de matéria orgânica apresentam maior CTC, porém com o predomínio $\mathrm{do}^{\mathrm{H}^{+}} \mathrm{e} \mathrm{Al}^{+3}$ no complexo de troca.

Tabela 3 - Relações de atributos químicos e fósforo remanescente.

\begin{tabular}{|c|c|c|c|c|c|c|c|c|c|}
\hline \multirow[b]{2}{*}{ Hor. } & \multirow{2}{*}{$\begin{array}{l}\text { Prof. } \\
(\mathrm{cm})\end{array}$} & \multirow{2}{*}{$\Delta \mathrm{pH}$} & SB & $\mathbf{t}$ & $\mathbf{T}$ & \multirow[t]{2}{*}{ V } & \multirow[t]{2}{*}{$\mathbf{m}$} & \multirow{2}{*}{$\begin{array}{l}\text { M.O. } \\
\text { g/kg-1 }\end{array}$} & \multirow{2}{*}{$\begin{array}{c}\text { P - Rem } \\
\text { mg. } \text { L }^{-1}\end{array}$} \\
\hline & & & \multicolumn{3}{|c|}{$\mathrm{cmol} / \mathrm{kg}$} & & & & \\
\hline \multicolumn{10}{|c|}{ P1 - NEOSSOLO QUARTZARÊNICO Órtico típico } \\
\hline A & $0-18$ & $-0,1$ & 0,2 & 2,3 & 11,5 & 2 & 91 & 38,40 & 44,4 \\
\hline$A C$ & $18-42$ & 0,16 & 0,2 & 0,5 & 4,5 & 3 & 72 & 14,10 & 26,8 \\
\hline $\mathrm{CA}$ & $42-81$ & 1,09 & 0,2 & 0,4 & 3,7 & 5 & 63 & 9,00 & 23,9 \\
\hline C1 & $81-112$ & 0,43 & 0,1 & 0,3 & 2,4 & 6 & 59 & 7,70 & 28,7 \\
\hline $\mathrm{C} 2$ & $112-180$ & 0,12 & 0,2 & 0,3 & 1,8 & 10 & 36 & 3,80 & 38,4 \\
\hline \multicolumn{10}{|c|}{ P2 - NEOSSOLO QUARTZARÊNICO Órtico espodossólico } \\
\hline A & $0-14$ & $-1,1$ & 0,2 & 0,8 & 2,8 & 7 & 79 & 9,00 & 58,1 \\
\hline$A C$ & $14-33$ & 0,32 & 0,2 & 1,1 & 4,5 & 4 & 83 & 10,20 & 35,1 \\
\hline $\mathrm{C} 1$ & $33-57$ & $-0,9$ & 0,2 & 0,2 & 1,3 & 17 & 0 & 2,60 & 51,9 \\
\hline $\mathrm{Bh} 1$ & $57-70$ & $-0,4$ & 0,2 & 0,6 & 3,7 & 6 & 63 & 11,50 & 20,7 \\
\hline Bh2 & $70-111$ & $-0,8$ & 0,2 & 0,5 & 2,5 & 9 & 56 & 6,40 & 27,6 \\
\hline BhC & $111-140$ & $-0,6$ & 0,1 & 0,4 & 1,7 & 7 & 71 & 2,60 & 36,2 \\
\hline C & $140-193$ & $-0,9$ & 0,2 & 0,6 & 1,5 & 14 & 65 & 2,60 & 42,1 \\
\hline \multicolumn{10}{|c|}{ P3 - ESPODOSSOLO HUMILÚVICO Hidromórfico arênico } \\
\hline A & $0-10$ & -1 & 0,3 & 0,6 & 2,2 & 12 & 61 & 9,00 & 62,8 \\
\hline $\mathrm{E}$ & 10_33 & $-0,54$ & 0,2 & 0,3 & 1,3 & 16 & 32 & 5,10 & 59,1 \\
\hline B1h & $33-61$ & $-0,39$ & 0,2 & 1,2 & 8,2 & 2 & 83 & 32,00 & 13,4 \\
\hline $\mathrm{B} 2 \mathrm{~h}$ & $61-77$ & $-0,82$ & 0,3 & 1,6 & 10,7 & 2 & 84 & 38,40 & 12,3 \\
\hline B3h & $77-94$ & $-0,37$ & 0,2 & 0,9 & 6,6 & 3 & 76 & 25,60 & 16,9 \\
\hline $\mathrm{C}$ & $94-125$ & $-0,08$ & 0,2 & 0,8 & 5,5 & 3 & 77 & 14,10 & 18,5 \\
\hline
\end{tabular}

SB: soma de bases; t: CTC efetiva; T: CTC potencial; V: Saturação por bases; m: saturação por alumínio; MO: matéria orgânica; P-rem: fósforo remanescente.

Fonte: Dados da pesquisa.

No perfil 1 o conteúdo de matéria orgânica é superior no horizonte $A$, e decresce gradualmente à medida que se aprofunda no perfil (Tabela 3). No perfil 2 o conteúdo de matéria orgânica é maior nos dois primeiros horizontes, havendo uma redução no horizonte $C$, seguido de incremento no horizonte Bh1. No perfil 3, o maior conteúdo de matéria orgânica é observado no horizonte Bh, e o menor encontrado no horizonte $\mathrm{E}$, considerado o horizonte de máxima eluviação. Os horizontes espódicos (Bh) são importantes no ciclo do carbono, devido a sua elevada capacidade de armazenar esse elemento, porém são ambientes com elevada fragilidade, principalmente com relação à erosão (MENDES et al., 2017).

Os teores de potássio são considerados baixos $(<0,1 \mathrm{cmol} / \mathrm{kg})$ nos perfis 1 e 3 , e médios $(0,1$ a 0,3 $\mathrm{cmol}_{\mathrm{l}} / \mathrm{kg}$ ) no perfil 2 (Tabela 2). Consequentemente com os baixos valores de $\mathrm{Ca}$ e $\mathrm{Mg}$, o valor de soma de bases será baixo. Devido à falta de nutrientes essenciais, as espécies vegetais de campinaranas se caracterizam por apresentar estresse nutricional (GUIMARÃES e BUENO, 2016). 
As frações mais finas do solo têm maior carga de superfície, permitindo assim alta capacidade de retenção de cátions trocáveis, de água e adsorção de fósforo, e o contrário, nas partículas maiores (solos arenosos) esses processos ocorrem de forma menos intensa. Isso influencia negativamente a aptidão do solo para a agricultura, devido a menor retenção de água e nutrientes, indispensáveis ao crescimento vegetal (FREIRE et al., 2013). Em solos com grande quantidade de areia, a exemplo dos Neossolos Quartzarênicos, tem se uma maior capacidade de drenagem, menor capacidade de armazenamento de nutrientes e baixo teor de matéria orgânica e estrutura do tipo grão simples (FREIRE et al., 2013).

Em termos gerais de fertilidade do solo, o perfil de Neossolo Quartzarênico apresenta- se com menor disponibilidade de nutrientes as plantas, entretanto apresenta maior CTC, sendo passível de melhoramento por meio de adubação e calagem. Os teores de Al trocável foram predominantemente médios na maioria dos horizontes, apenas os horizontes $A$ e Bh2 dos perfis 1 e 3 , respectivamente apresentam altos teores desse elemento (AMARAL e SOUZA, 1998). Assim como Espodossolos e Neossolos de outras regiões Amazônicas, os solos da área de estudo se caracterizam como ácidos e de baixa fertilidade (MENDONÇA et al., 2015).

\section{CONSIDERAÇÕES FINAIS}

Os solos estudados, em razão de sua natureza predominantemente arenosa, caracterizam-se por serem distróficos (oligotróficos), de baixa CTC e elevada saturação de alumínio (m\%) e com maior predisposição a processos erosivos, o que inviabiliza seu uso agrícola, pecuário e florestal.

Os Espodossolos, que ocorrem na porção inferior da paisagem, estão sujeitos a maior restrição de drenagem, que condiciona a presença de horizonte Bh menos endurecido, em razão da perda de $\mathrm{Fe}$ e Al por redução, elementos estes que conferem efeito cimentante.

Em síntese, as condições de baixa fertilidade natural dos solos e de restrição de drenagem tornam o ambiente propício ao acúmulo de material vegetal em virtude da baixa atividade microbiana.

Considerando a fragilidade física dos solos e o endemismo desse ecossistema, são necessárias ações que visem a preservação e/ou conservação de forma a reduzir a pressão antrópica, a exemplo de unidades de conservação.

Estudos adicionais são necessários com relação ao conteúdo, natureza e dinâmica dos compostos orgânicos em superfície (Horizonte A) e subsuperficie (Horizonte Bh).

\section{REFERÊNCIAS}

ACRE. Secretaria de Estado de Meio Ambiente (SEMA). Recursos naturais: geologia, geomorfologia e solos do Acre. Programa Estadual de Zoneamento Ecológico-Econômico do Acre- ZEE/AC fase II, escala 1:250.000. Rio Branco: SEMA Acre, 2010. 100 p.

AMARAL. E. F.; SOUZA, A. N. Avaliação da fertilidade do solo no Sudeste Acreano: O caso do PED/MMA no município de Senador Guiomard. Rio Branco: Embrapa Acre, 1998. 35 p. (Documentos, 26)

BRITO, T. de F.; SILVA, R. de C.; OLIVEIRA, S. A. V. de; SILVEIRA, M. (Org.). Complexo vegetacional sobre areia branca: campinaranas do sudoeste da Amazônia. Rio Branco, AC: Edufac, 2017. 93 p.

CAVALCANTE, L. M. Zoneamento Geológico e Geomorfológico entre Feijó e Mâncio Lima Acre. Rio Branco: Embrapa Acre, 2005. 24 p. (Embrapa Acre. Documentos, 99)

CUNHA, T. J.; MENDES, A. M. S.; GIONGO, V. Matéria orgânica do solo. In: NUNES, R. R.; REZENDE, M. O. O. (org.). Recurso solo: propriedades e usos. São Carlos: Cubo, 2015. p. 273-293.

DALL'IGNA, L. G.; SILVA, R. M.; Áreas de relevante interesse mineral e restrições as atividades de mineração. In: ADAMY, A. (org.). Geodiversidade do estado do Acre. Porto Velho: CPRM, 2015. p. 73-84. 
DALMOLIN, R. S. D.; GONÇALVES, C. N.; KLAMT, E.; DICK, D. P. Relação entre os constituintes do solo e seu comportamento espectral. Ciência Rural, Santa Maria, RS, v. 35, n. 2, p. 481-489, mar./abr. 2005. https://doi.org/10.1590/S0103-84782005000200042

DALY, C. D.; PRANCE, G. T.. Brazilian Amazon. In: CAMPBELL, D. G.; HAMMOND, H. D. (EDS.). Floristic inventory of tropical countries. NY: New York Botanical Garden, 1989. p. 401-426.

DALY, C. D.; SILVEIRA, M. Aspectos florísticos da bacia do Alto Juruá: história botânica, peculiaridades, afinidades e importância para a conservação. $p$ In: CUNHA \& ALMEIDA (Orgs.) Enciclopédia da Floresta. São Paulo: Companhia das Letras, 2002.p. 53-63.

DALY, D. C., M. SILVEIRA, V. PASSO, E. F. AMARAL, C. I. SALIMON, A. KIRCHGESSNER, WADT,P. G. S. First catalogue of the flora of Acre, Brazil/Primeiro Catálogo da Flora do Acre, Brasil. Rio Branco: PRINTAC/EDUFAC, 2008. 555 p.

DALY, D.; SILVEIRA, M.; MEDEIROS, H.; CASTRO, W.; OBERMÜLLER, F.A.. The White-sand Vegetation of Acre, Brazil. Biotropica, Malden Massachusetts, EUA, v. 48, n.1, p. 81-89, jan. 2016. https://doi.org/10.1111/btp.12307

DIAS, D. de M.; PAGOTTO, M. A.; PEREIRA, T. C.; RIBEIRO, A de S. Estrutura arbórea e sazonalidade da cobertura do dossel em vegetação florestada e aberta no Parque Nacional Serra de Itabaiana, Sergipe, Brasil. Ciência Florestal, Santa Maria-RS,v. 27, n. 2, p. 719-729, abr./jun. 2017. https://doi.org/10.5902/1980509827757

FERREIRA, L. V.; CHAVES, P. P.; CUNHA, D. A.; ROSÁRIO, A. S.; PAROLIN, P. A extração ilegal de areia como causa do desaparecimento de campinas e campinaranas do estado do Pará, Brasil. Pesquisas - Botânica, São Leopoldo, n. 64, p. 157-173, jan/dez. 2013.

FILGUEIRA, V.; ARAÚJO, E. A. ; SILVA, Y. D. ; OLIVEIRA, N. ; LIMA, N. S. Impactos da extração de areia em ambiente de Campinarana Florestada, Vale do Juruá, Acre. In: SEFLOR SEMANA DE ENGENHARIA FLORESTAL DO CAMPUS FLORESTA, 5, 2020, Cruzeiro do Sul. Anais... Cruzeiro do Sul: UFAC, 2020.

FREIRE, L. C. (coord.). Manual de calagem e adubação do estado do Rio de Janeiro. Brasília: Embrapa, 2013. 430 p.

GUIMARÃES, F. S.; BUENO, G. T. As campinas e campinaranas amazônicas. Caderno de Geografia, Belo Horizonte, v. 26, n. 45, p. 113-133, jan./abr. 2016. https://doi.org/10.5752/P.23182962.2016v26n45p113

GUIMARÃES, F. S.; BUENO, G. T.; MENDES, D. de S. O.; NASCIMENTO, N. R. do; DINIZ, A. D.; SOUZA, J. B. de. Dinâmica vegetal e evolução da paisagem no contato entre campinarana e campina sobre Espodossolos - bacia do Rio Demini- AM (Brasil). Revista Brasileira de Geomorfologia, São Paulo, v. 19, n. 3, p. 587-600, jul./set. 2018. https://doi.org/10.20502/rbg.v19i3.1288

IBGE, Instituto Brasileiro de Geografia e Estatística. Diretoria de Geociências. Coordenação de Recursos Naturais e Estudos Ambientais. Projeto Sistematização das Informações Sobre Recursos Naturais. 2000.

IBGE. Instituto Brasileiro de Geografia e Estatística.. Manual técnico da vegetação brasileira. Rio de Janeiro:IBGE, 1992. 92 p. (Manuais Técnicos em Geociências)

LIMA, C. G. da R.; CARVALHO, M. de P. e; SOUZA, A.; COSTA, N. R.; MONTANARI, R. Correlação entre componentes da produtividade da cana-de-açúcar com pH de um Argissolo Vermelho Distrófico do noroeste paulista. Engenharia na Agricultura, Viçosa, MG, v. 24, n. 2, p. 120-130, abr. 2016. https://doi.org/10.13083/reveng.v24i2.592

MENDES, D. de S. O.; BUENO, G. T.; GUIMARÃES, F. S.; ROSSIN, B. G.; NASCIMENTO, N. R. do. Os solos e geoambientes das campinaranas amazônicas: relação genética entre os geoambientes e a evolução da paisagem em um transecto na bacia do Alto Rio Negro, Amazônia. Revista Brasileira de Geomorfologia, São Paulo, v. 18, n. 3, p. 547-559, jul./set. 2017. https://doi.org/10.20502/rbg.v18i3.1192 
MENDONÇA, M. A. F. de; FERNANDES FILHO, E. I.; SHAEFER, C. E. G. R.; SIMAS, F. N. B.; PAULA, M. D. de. Os solos das campinaranas na Amazônia brasileira: Ecossistemas arenícolas e oligotróficos. Ciência Florestal, Santa Maria, v. 25, n. 4, p. 827-839, out./dez. 2015. https://doi.org/10.5902/1980509820581

MUNSELL. Soil color charts. Baltimore: Munsell Color Company, 1994. 28p.

OLIVEIRA, A. A. de; DALY, D. C.; VICENTINI, A.; COHN-HAFT, M. Florestas sobre areia: campinaranas e igapós. In: OLIVEIRA, A. A. de; DALY, D. C. (ed.). Florestas do Rio Negro. São Paulo: Companhia das Letras, 2001. p. 179-219.

SANTOS, H. G. dos; JACOMINE, P. K. T.; ANJOS, L. H. C. dos; OLIVEIRA, V. A. de; LUMBRERAS, J. F.; COELHO, M. R.; ALMEIDA, J. A. de; ARAÚJO FILHO, J. C. de; OLIVEIRA, J. B. de; CUNHA, T. J. F. Sistema brasileiro de classificação de solos. 5 ed. rev e ampl. Brasília: Embrapa, 2018.

SANTOS, R. D.; LEMOS, R. C.; SANTOS, H. G.; KER, J. C. Manual de descrição e coleta de solo no campo. 6 ed. Sociedade Brasileira de Ciência do Solo: Viçosa, 2013.

SCHAEFER, C. E. G. R.; MENDONÇA, B. A. R.; FERNANDES FILHO, E. I. Geoambientes e paisagens do parque nacional do Viruá, Roraima: esboço de integração da climatologia, solos, hidrologia e ecologia. Relatório Técnico/ICMBio, 2009. 51p.

SILVA, A. L. C. ; ARAÚJJ, E. A. Impactos ambientais causados pela extração de areia em ambiente de Campinarana na Amazonia Sul Ocidental. In: SEFLOR SEMANA DE ENGENHARIA FLORESTAL DO CAMPUS FLORESTA, 5, 2020, Cruzeiro do Sul. Anais... Cruzeiro do Sul: UFAC, 2020.

TEIXEIRA, P. C.; DONAGEMMA, G. K.; FONTANA, A.; TEIXEIRA, W. G. (ed.) Manual de métodos de análise de solo. 3 ed. rev. ampl. Brasília: Embrapa, 2017. 573 p.

VELOSO, H. P.; RANGEL FILO, A. L .R.; LIMA, J. C. A.. Classificação da vegetação brasileira, adaptada a um sistema universal. Rio de Janeiro. IBGE, 1991.123 p.

VICENTINI, A. A.. Vegetação ao longo de um gradiente edáfico no parque nacional do Jaú. In: BORGES, S. H.; IWANAGA, S.; DURIGAN, C. C.; PINHEIRO, M. R. (Eds.). Janelas para a biodiversidade no parque nacional do Jaú: uma estratégia para o estudo da biodiversidade na Amazônia. Manaus: Fundação Vitória Amazônica (FVA)/WWF/IBAMA, 2004. p.117-143.

WADT, P. G. S; CRAVO, M. S. Interpretação de resultados de análises de solos. In: WADT, P. G. S. (ed.) Manejo do solo e recomendação de adubação para o estado do Acre. Rio Branco: Embrapa Acre, 2005. p. 245-252.

Recebido em: 24/09/2019

Aceito para publicação em: 31/03/2020 